mgr inz. Michat Kowalski

mgr inz. Jacek Ostrowski

mgr inż. Krzysztof Przepióra

Instytut Pojazdów Szynowych ,TABOR”

\title{
Wpływ hałasu i drgań na środowisko pracy w odniesieniu do pojazdów szynowych.
}

\begin{abstract}
Hatas $i$ wibracje sq to wszelkie niepożq̨dane, nieprzyjemne, dokuczliwe, uciażliwe lub szkodliwe drgania mechaniczne ośrodka sprężystego, działajace za pośrednictwem powietrza na organ stuchu i inne zmysty oraz elementy organizmu człowieka. Sa to formy zanieczyszczenia środowiska przyrodniczego, charakteryzujace się mnogościq źródet i powszechnościq występowania.
\end{abstract}

Głównym źródłem hałasu i drgań dla pojazdu szynowego jest punkt styku koła z szyną. W czasie poruszania się pojazdu szynowego na styku koła z szyną generowane są drgania mechaniczne. Część tych drgań jest emitowana w postaci fal akustycznych, rozchodzących się w powietrzu i odbieranych przez człowieka jako dźwięk. Pozostała część tych drgań przenosi się na konstrukcję nawierzchni oraz na konstrukcje pojazdu, i ma wpływ na ludzi znajdujących się w pojeździe. Te drgania mechaniczne które propagują się w ośrodkach stałych zwane są w ochronie środowiska wibracjami, a w dynamice konstrukcji najczęściej wprost drganiami. Zjawiska te wpływają ujemnie zarówno na ludzi znajdujących się $\mathrm{w}$ pojeździe jak i $\mathrm{w}$ bezpośrednim jego otoczeniu.

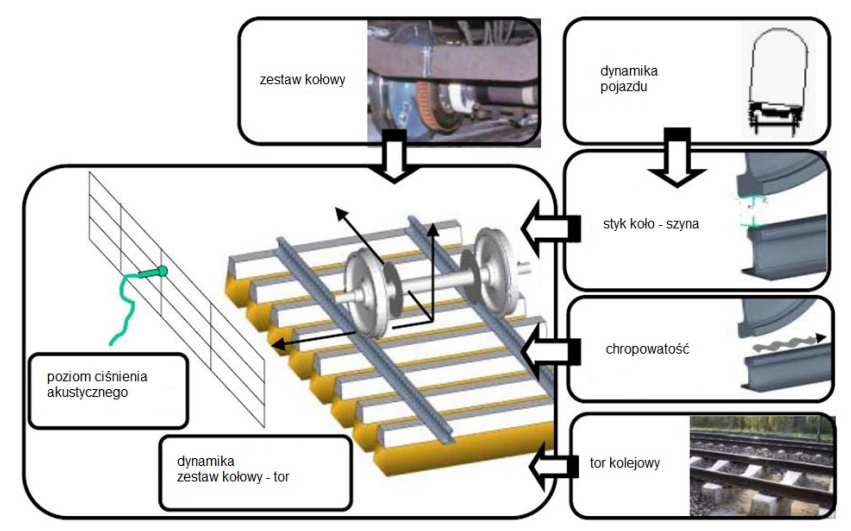

Oddziaływania wibroakustyczne (hałas i drgania) generowane przez pojazdy szynowe maja negatywny wpływ na obsługe pojazdów jak i na pasażerów. Szczególnie jest to ważne w odniesieniu do obsługi pojazdów gdyż długotrwała ekspozycja na oddziaływanie wibroakustyczne może powodować pogorszenie samopoczucia, zmęczenie, zmniejszenie efektywności działania co ma bezpośredni wpływ na bezpieczeństwo prowadzenia pociagów.

\section{Pomiar halasu w kabinie maszynisty}

Instytut Pojazdów szynowych TABOR od lat wykonu- je badania mające na celu określenie hałasu wewnątrz jak i na zewnątrz pojazdu. Kompleksowe badania hałasu pojazdu wykonuje się w oparciu o wymagania zawarte w następujących dokumentach i normach: PN-92/K-11000 [1], PN-EN 15892:2011 [2], PN EN ISO3095 [3], TSI-Hałas [4], PN-86/N-01338 [5], PN-Z01338:2010 [6], PN-ISO 7196:2002 [7], PN-86/N-01321 [8], w Rozporządzeniu MPiPS z 28.11.2002 (Dz.U. Nr 217 poz.1833) [9], TSI - Loc\&pas [10], PN-91/K-88100 [11].

Należy zwrócić uwage że w przypadku hałasu wewnątrz pojazdu dodatkowy źródłem hałasu emitowanym przez pojazd jest hałas aerodynamiczny. Dla pojazdów poruszających się z prędkością powyżej $140 \mathrm{~km} / \mathrm{h}$ wzrost hałasu wynikający $\mathrm{z}$ oporów aerodynamicznych zaczyna być zauważalny.

Zakres badań pojazdu szynowego obejmuje następujące zagadnienia:

1.Pomiary w kabinie maszynisty

- pomiar hałasu słyszalnego

- pomiar hałasu ultradźwiękowego

- pomiar hałasu infradźwiękowego

2. Pomiar poziomu dźwięku oraz częstotliwości tonu emitowanych przez sygnalizatory akustyczne (na zewnątrz i wewnątrz pojazdu).

3. Pomiar na zewnątrz od przejeżdżającego pojazdu.

4. Pomiar na zewnątrz od ruszającego pojazdu.

$\mathrm{W}$ odniesieniu do środowiska w jakim znajduje się obsługa pojazdów szynowych poniżej przedstawiono przykładowe wyniki badań dla lokomotywy spalinowej o mocy $2400 \mathrm{~kW}$ w zakresie hałasu zmierzonego w kabinie maszynisty:

Hałas infradźwiękowy $\mathrm{w}$ pasmach oktawowych $\mathrm{w}$ zakresie od $0.5 \mathrm{~Hz}$ do $31.5 \mathrm{~Hz}$. Kolorem czerwonym zaznaczono wartości zbliżone do kryterium ( maksymalny poziom dźwięku $\mathrm{L}_{\mathrm{pGeq}, 8 \mathrm{~h}} \leq 102[\mathrm{~dB}]$ )

Przebieg ciśnienia akustycznego w pasmach oktawowych oraz poziomu dźwięku wewnątrz lokomotywy spalinowej podczas postoju i jazdy. Załączony układ grzewczo - klimatyzacyjny. Kabina 2; dane w tabeli 


\begin{tabular}{|l|l|l|l|l|l|l|}
\hline \multicolumn{6}{|l|}{ Średni poziom dźwięku $\mathrm{L}_{\text {pGeq,T }}[\mathrm{dB}]$ w kabinach maszynisty } \\
\hline $\begin{array}{l}\text { Wariant } \\
\text { nawiewu }\end{array}$ & Kabina 1 & \multicolumn{1}{l|}{ Kabina 2} \\
\cline { 2 - 7 } & $0 \mathrm{~km} / \mathrm{h}$ & $80 \mathrm{~km} / \mathrm{h}$ & $160 \mathrm{~km} / \mathrm{h}$ & $0 \mathrm{~km} / \mathrm{h}$ & $80 \mathrm{~km} / \mathrm{h}$ & $160 \mathrm{~km} / \mathrm{h}$ \\
\hline 0 & 78,5 & 90,5 & 101,5 & 76,6 & 91,0 & 100,2 \\
\hline $\mathrm{K}$ & 79,7 & 89,6 & 101,6 & 71,1 & 92,0 & 100,6 \\
\hline
\end{tabular}

0 - wytaczony uklad grzewczo - klimatyzacyjny

$K$-załaczony uktad grzewczo - klimatyzacyjny

Hałas słyszalny $w$ pasmach oktawowych $w$ zakresie od $31.5 \mathrm{~Hz}$ do $8 \mathrm{kHz}$. Kolorem czerwonym zaznaczono wartości zbliżone do kryterium ( maksymalny poziom dźwięku $\mathrm{L}_{\mathrm{pAeq}, \mathrm{T}} \leq 78[\mathrm{~dB}]$ ); dane w tabeli

\begin{tabular}{|l|l|l|l|l|l|l|}
\hline \multicolumn{6}{|l|}{ Średni poziom dźwięku $\mathrm{L}_{\mathrm{pAeq} . \mathrm{T}}[\mathrm{dB}]$ w kabinach maszynisty } \\
\hline \multirow{2}{*}{$\begin{array}{l}\text { Wariant } \\
\text { nawiewu }\end{array}$} & Kabina 1 & \multicolumn{1}{l|}{ Kabina 2} \\
\hline 0 & $0 \mathrm{~km} / \mathrm{h}$ & $80 \mathrm{~km} / \mathrm{h}$ & $160 \mathrm{~km} / \mathrm{h}$ & $0 \mathrm{~km} / \mathrm{h}$ & $80 \mathrm{~km} / \mathrm{h}$ & $160 \mathrm{~km} / \mathrm{h}$ \\
\hline $\mathrm{K}$ & 66,0 & 71,6 & 76,4 & 70,4 & 69,2 & 75,5 \\
\hline
\end{tabular}

0 - wyłaczony układ grzewczo - klimatyzacyjny

$K$ - załaczony uktad grzewczo - klimatyzacyjny

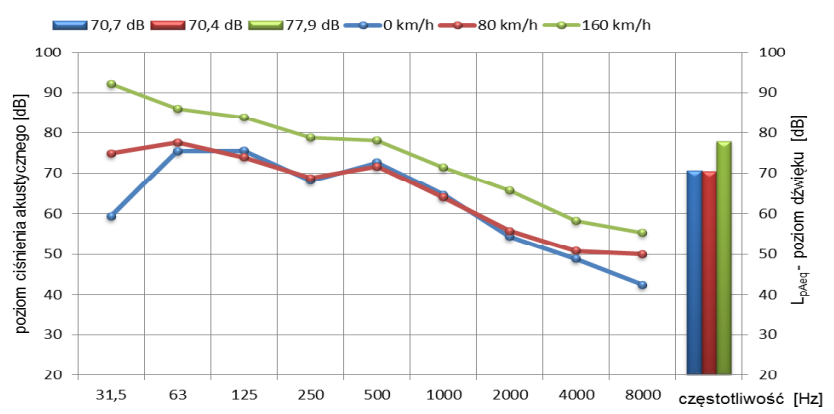

Halas ultradźwiękowy $w$ pasmach tercjowych w zakresie od $10 \mathrm{kHz}$ do $20 \mathrm{kHz}$. Kolorem czerwonym zaznaczono wartości zbliżone do kryterium ( maksymalny poziom dźwięku $\mathrm{L}_{\mathrm{dop}} \leq 90[\mathrm{~dB}]$ )

\begin{tabular}{|l|l|l|l|l|l|l|}
\hline \multicolumn{6}{|c|}{ Średni poziom dźwięku L [dB] w kabinach maszynisty } \\
\hline \multirow{2}{*}{$\begin{array}{l}\text { Wariant } \\
\text { nawiewu }\end{array}$} & Kabina 1 & \multicolumn{1}{l|}{ Kabina 2} \\
\hline & $0 \mathrm{~km} / \mathrm{h}$ & $80 \mathrm{~km} / \mathrm{h}$ & $160 \mathrm{~km} / \mathrm{h}$ & $0 \mathrm{~km} / \mathrm{h}$ & $80 \mathrm{~km} / \mathrm{h}$ & $160 \mathrm{~km} / \mathrm{h}$ \\
\hline 0 & 38,9 & 37,8 & 43,0 & 38,5 & 34,6 & 42,6 \\
\hline $\mathrm{K}$ & 40,2 & 38,5 & 42,6 & 34,3 & 45,7 & 49,5 \\
\hline
\end{tabular}

0 - wytaczony uktad grzewczo - klimatyzacyjny

$K$ - załaczony uktad grzewczo - klimatyzacyjny

\section{Pomiar drgań na stanowisku pracy maszynisty}

Badania drgań na stanowisku pracy maszynisty realizuje się poprzez pomiar przyspieszeń w kabinie maszynisty w następujących punktach:

na fotelu maszynisty $w$ trzech kierunkach występowania drgań $(X, Y, Z)$,

na podłodze $w$ trzech kierunkach występowania drgań $(\mathrm{X}, \mathrm{Y}, \mathrm{Z})$.

Pomiary i ocenę poziomu przyspieszenia drgań na stanowisku pracy maszynisty w kabinach realizuje się w oparciu o Rozporządzenie Ministra Transportu, Budownictwa i Gospodarki Morskiej, normy: PN91/N-01352:1991 [12], PN-90/K-11003:1990 [13], PN-90/K-11001:1990 [14], PN-91/N-01354:1991 [15], ERRI B153 Rp8 [16], ERRI B153 Rp 23 [17], ISO
2631 [18] oraz Rozporządzenie MPiPS z dnia 29 listopada 2002 r. [19] i Rozporządzenie MGiP z dnia 10 października 2005 r [20].

Ocena końcowa wpływu drgań na stanowisku pracy maszynisty nie powinien przekraczać granicy uciążliwości dla 8-mio godzinnej zmiany roboczej. Wartości graniczne przedstawiono w tabeli poniżej:

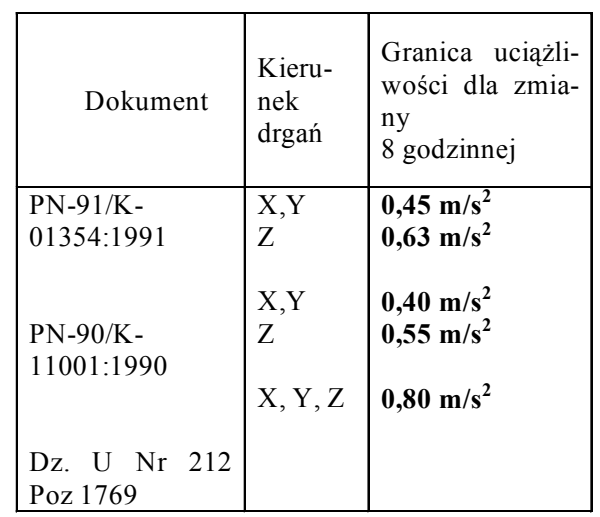

W tabeli poniżej przedstawiono wyniki z badań drgań w kabinach maszynisty lokomotywy spalinowej o mocy $2400 \mathrm{~kW}$. Tabela zawiera wartości ważone przyspieszenia drgań dla całości jazd $\mathrm{a}_{\mathrm{w}} \mathrm{z}$ wykorzystaniem filtrów Griffina i ISO. Ważone wartości przyspieszenia uwzględniają prawdopodobieństwo postoju i jazdy z daną prędkością. Badana lokomotywa spalinowa przeznaczona jest do prowadzenia pociagów towarowych z prędkością do $100 \mathrm{~km} / \mathrm{h}$ oraz pociagów osobowych z prędkością do $160 \mathrm{~km} / \mathrm{h}$

\begin{tabular}{|c|c|c|c|c|c|c|c|}
\hline & \multirow{3}{*}{$\begin{array}{c}\text { Kienunek } \\
\text { jazdy }\end{array}$} & \multicolumn{3}{|c|}{ Filtry Griffina } & $\begin{aligned} \text { spieszen } \\
\text { (ERRI B }\end{aligned}$ & (ERRI B153) & \\
\hline & & \multicolumn{3}{|c|}{ Fotel } & \multicolumn{3}{|c|}{ Podłoga } \\
\hline & & $\begin{array}{l}\text { Poziom } \\
\text { wzdł. X }\end{array}$ & $\begin{array}{l}\text { Poziom } \\
\text { poprz. Y }\end{array}$ & $\begin{array}{l}\text { Pion } \\
Z\end{array}$ & $\begin{array}{l}\text { Poziom } \\
\text { wzdk. X }\end{array}$ & $\begin{array}{l}\text { Poziom } \\
\text { poprz. Y }\end{array}$ & $\begin{array}{c}\text { Pion } \\
Z\end{array}$ \\
\hline Ruch & 1 & 0.03 & 0.06 & 0.07 & 0.01 & 0.05 & 0.06 \\
\hline towarowy & 2 & 0.04 & 0.07 & 0.06 & 0.02 & 0.06 & 0.06 \\
\hline Ruch & 1 & 0.05 & 0.15 & 0.12 & 0.03 & 0.14 & 0.17 \\
\hline \multirow[t]{4}{*}{ pasażerski } & 2 & 0.08 & 0.18 & 0.13 & 0.03 & 0.17 & 0.17 \\
\hline & \multirow{3}{*}{$\begin{array}{c}\text { Kienunek } \\
\text { jazdy }\end{array}$} & \multicolumn{6}{|c|}{$\begin{array}{l}\text { Ważone wartości przyspieszenia } \mathrm{a}_{\mathrm{w}}\left[\mathrm{m} / \mathrm{s}^{2}\right] \\
\text { Filtry ISO (ISO-2631) }\end{array}$} \\
\hline & & \multicolumn{3}{|c|}{ Fotel } & \multicolumn{3}{|c|}{ Podłoga } \\
\hline & & $\begin{array}{l}\text { Poziom } \\
\text { wzdł. X }\end{array}$ & $\begin{array}{l}\text { Poziom } \\
\text { poprz. Y }\end{array}$ & $\begin{array}{l}\text { Pion } \\
Z\end{array}$ & $\begin{array}{l}\text { Poziom } \\
\text { wzdk. X }\end{array}$ & $\begin{array}{l}\text { Poziom } \\
\text { poprz. Y }\end{array}$ & $\begin{array}{c}\text { Pion } \\
Z\end{array}$ \\
\hline Ruch & 1 & 0.03 & 0.06 & 0.08 & 0.01 & 0.05 & 0.07 \\
\hline towarowy & 2 & 0.04 & 0.07 & 0.07 & 0.02 & 0.06 & 0.07 \\
\hline Ruch & 1 & 0.05 & 0.15 & 0.14 & 0.03 & 0.14 & 0.18 \\
\hline pasażerski & 2 & 0.08 & 0.18 & 0.15 & 0.03 & 0.18 & 0.18 \\
\hline
\end{tabular}

Kolorem czerwonym zaznaczono wartości o największej wartości

\section{Podsumowanie}

Na podstawie przedstawionych wyników oraz wieloletnich badań można stwierdzić iż wartości drgań oddziaływujących na obsługę pojazdów jest na poziomie o wiele niższym niż kryteria zawarte w normach określających poziom tych drgań. Na tak sytuację mają wpływ dwa czynniki: poprawa infrastruktury po której porusza się pojazd i nowo konstruowane pojazdy które charakteryzuja się lepszymi rozwiązaniami konstrukcyjnymi $\mathrm{w}$ dziedzinie zawieszenia co ma bezpośredni wpływa na lepsze tłumienie wymuszeń wynikających z kontaktu koło szyna. Natomiast 
w przypadku hałasu na jaki narażona jest obsługa w kabinach maszynisty rejestrowane poziomy dźwięku są na dość wysokim poziomie często na granicy jakie określają normy. Dlatego należy podjąć działania mające na celu zmianę podejścia konstruktorów przy projektowaniu kabin. Należy wprowadzić konieczne zmiany w konstrukcji kabiny które przyczynią się do zapewnienia bardziej komfortowych, a zarazem bezpieczniejszych warunków pracy maszynisty (izolacja, konstrukcja okien i drzwi).

\section{Dokumenty odniesienia}

[1] PN-92/K 11000

[2] PN-EN 15892:2011

[3] PN-EN ISO-3095:2005

[4] TSI-Hałas

[5] $P N-86 / N-01338$

[6] PN-Z 01338:2010

[7] PN-ISO 7196:2002

[8] PN-86/N-01321

[9] Dz.U. Nr 217 poz. 1833

[10] TSI-Loc\&pas

[11] PN-91/K-88100

[12] $P N-91 / N-01352: 1991$

[13] PN-90/K-11003:1990

[14] PN-90/K-11001:1990

[15] PN-91/K-01354:1991

[16] ERRI B153 Rp8

[17] ERRI B153 Rp 23

[18] ISO 2631

[19] Dz.U.Nr 217 poz.1833

[20] Dz.U.Nr 212 poz.1769
Tabor kolejowy. Hałas. Ogólne wymagania i badania.

Emisja hałasu. Pomiar hałasu wewnatrz kabin maszynisty.

Kolejnictwo. Akustyka. Pomiar hałasu emitowanego przez pojazdy szynowe.

Decyzja Komisji Europejskiej $z$ dnia 4 kwietnia 2011 r. TSI C(2011)658 dotyczaca technicznej specyfikacji dla interoperacyjności odnoszacej się do technicznej specyfikacji interoperacyjności odnoszacej się do podsystemu „,Tabor kolejowy - hałas” transeuropejskiego systemu kolei konwencjonalnych. Obowiazuje od 13 kwietnia 2011 r. Dz.U.UE nr L99.

Hałas infradźwiękowy. Dopuszczalne wartości poziomów ciśnienia akustycznego na stanowiskach pracy $i$ ogólne wymagania dotyczqce pomiarów.

Akustyka. Pomiar i ocena hałasu infradźwiękowego na stanowisku pracy.

Akustyka. Charakterystyka częstotliwościowa filtru do pomiarów infradźwięków.

Hałas ultradźwiękowy. Dopuszczalne wartości poziomu ciśnienia akustycznego na stanowiskach pracy i ogólne wymagania dotyczqce pomiarów.

Rozporzadzenie Ministra Pracy $i$ Polityki Społecznej z dnia 28.11.2002 r. w sprawie najwyższych dopuszczalnych stężeń i natężeń czynników szkodliwych dla zdrowia w środowisku pracy

Decyzja $n r$ 2011/291/UE Komisji $z$ dnia 26.04. 2011 r. TSI C(2011)2737 w sprawie interoperacyjności odnoszacej się do podsystemu „,Tabor - lokomotywy i tabor pasazerski” $w$ transeuropejskim systemie kolei konwencjonalnych

Pojazdy trakcyjne. Syreny i gwizdawki.

Drgania. Zasady wykonywania pomiarów na stanowiskach pracy. Wycofana bez zastapienia, z możliwościa stosowania.

Ochrona pracy. Kabina maszynisty lokomotywy elektrycznej dwukabinowej. Metodyka badań drgań.

Wycofana bez zastapienia, z możliwościa stosowania.

Ochrona pracy. Kabina maszynisty lokomotyw elektrycznej dwukabinowej. Podstawowe wymagania bezpieczeństwa pracy i ergonomii. Wycofana bez zastapienia, z możliwościq stosowania.

Drgania. Dopuszczalne wartości przyspieszenia drgań o ogólnym oddziaływaniu na organizm człowieka i metody oceny narażenia.

Wycofana bez zastapienia, z możliwościa stosowania.

Użycie normy ISO 2631 do pojazdów kolejowych. Utrecht 04.1989r.

Zastosowanie normy ISO $2631 \mathrm{w}$ pojazdach kolejowych. Sprawozdanie - synteza. Utrecht, 12.1993r.

Drgania mechaniczne $i$ wstrzasy oddziaływujace na czlowieka.

Rozporzqdzenie Ministra Pracy i Polityki Społecznej z dnia Zat. 2 pkt B 29.11.2002 r. w sprawie najwyższych dopuszczalnych stężeń $i$ natężeń czynników szkodliwych dla zdrowia w środowisku pracy.

Rozporzqdzenie Ministra Gospodarki i Pracy z dnia 10.10.2005 r. zmieniajace rozporzadzenie $w$ sprawie najwyższych dopuszczalnych stężen $i$ natężeń czynników szkodliwych dla zdrowia w środowisku pracy. 